\title{
Participação e política pública: efetividade dos conselhos de assistência social na gestão da política
}

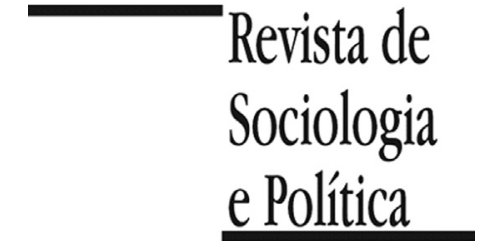

DOI $10.1590 / 1678987318266704$

\author{
Euzeneia Carlos'iD, Rafael da Silva"iid e \\ Carla Almeida"I
}

RESUMO Introdução: Este artigo pretende contribuir com o debate em curso sobre a efetividade das instituições participativas, analisando os efeitos dos conselhos de assistência social sobre a gestão da política setorial nos municípios brasileiros. Métodos: Metodologicamente, a análise estabelece uma correlação estatística entre a efetividade da participação e o desempenho da gestão da política a partir da construção de dois índices, o Índice de Efetividade da Participação (IEP) e o Índice de Gestão Municipal (IGM), utilizando os dados do Censo SUAS de 2012. O primeiro índice agrega indicadores da qualidade da participação expressos no grau de institucionalização, deliberação e representação. O segundo reúne variáveis relativas ao desempenho da gestão na política setorial, mensurado pelas capacidades técnico-administrativas presentes nos municípios. Resultados: A contribuição do artigo consiste em aferir os efeitos dos conselhos de assistência social sobre a política setorial, além de discutir sob quais condições a participação importa aos municípios. Ressalta-se dois condicionantes que incidem sobre os resultados da participação na gestão da política: o pertencimento regional e o porte populacional. Discussão: Argumenta-se que a efetividade da participação explica uma parcela maior da variação do desempenho da gestão nos municípios de menor porte populacional, o que remete à configuração da política pública.

PALAVRAS-CHAVE: instituições participativas; municípios brasileiros; conselhos gestores; gestão pública; assistência social.

Recebido em 7 de Agosto de 2017. Aceito em 24 de Dezembro de 2017.

\section{Introdução ${ }^{1}$}

\footnotetext{
${ }^{1}$ Este artigo é produto da pesquisa "Efetividade do controle social na política de assistência social", financiada pelo CNPq (Edital Ciências Humanas, $N^{\circ} 43 / 2013$ ). Agradecemos aos comentários e sugestões dos pareceristas anônimos da Revista de Sociologia e Política.
}

$\mathrm{E}$ ste artigo pretende contribuir com o debate em curso sobre a efetividade das Instituições Participativas (IPs), analisando os efeitos da participação nos conselhos de assistência social sobre a gestão dessa política na esfera municipal. Mensurar a efetividade da participação e perscrutar sob quais condições a participação importa constitui uma problemática central para os estudiosos dessa agenda de pesquisa. A crescente expansão das IPs e sua institucionalização no Estado tornou incontornável a necessidade de aferir seus efeitos no desempenho da política pública e no funcionamento dos governos, tarefa que se tornou particularmente importante em face das recentes mudanças ocorridas na política brasileira que tornaram incerta a continuidade dessa expansão e o próprio futuro das instituições participativas no país..

A agenda de estudos sobre a efetividade das IPs tem assumido, compreensivelmente, duas direções (Avritzer 2010). Na primeira, os estudos buscam construir indicadores para aferir a efetividade deliberativa nas IPs, ou a qualidade da deliberação em termos de sua capacidade de promover ideais como a igualdade, a inclusão, a publicidade e a pluralidade (Smith 2009; Almeida \& Cunha 2011; Cunha 2010; Faria \& Ribeiro 2011). Sob esse enfoque, os trabalhos analisam o processo de deliberação no interior dos arranjos participativos e sua qualidade, avaliando sua dinâmica de funcionamento e os condicionantes de sua efetividade. Nessa análise, torna-se essencial a maneira como os ideais deliberativos são promovidos a partir das regras e do funcionamento das instituições (Saward 2000). Assim, o desenho institucional é uma medida importante, pois indicam as regras que regulam a dinâmica decisória e definem seu 
raio de jurisdição: quem são, quem seleciona e quantos são os participantes (Faria \& Ribeiro 2011; Almeida \& Cunha 2011). Para esse primeiro grupo, portanto, a efetividade da deliberação é analisada por meio de indicadores que permitem aferir a qualidade do processo deliberativo nas IPs.

Na segunda, os estudos assumem as IPs como variável explicativa e indagam sobre sua capacidade de produzir resultados (outcomes) ou efeitos sobre as políticas públicas e sobre o funcionamento dos governos. Comumente identificados como efetividade das instituições participativas, esse agrupamento de estudos se ancora na integração disciplinar entre a tradição da democracia deliberativa e a abordagem de avaliação de políticas públicas (Pires \& Vaz 2010). Nessa linha de pensamento, os analistas enfocam a importância das inovações democráticas no contexto em que as eleições não são suficientes para responsabilizar os governos em relação à melhoria da vida dos cidadãos, principalmente dos mais pobres (Donaghy 2013). Entretanto, o reconhecimento de que precisamos de mais informações sobre a capacidade de as inovações democráticas efetivamente gerarem respostas por parte dos governos é igualmente crescente. Segundo Donaghy (2013), ainda não temos evidências suficientes dessa capacidade e não sabemos sob que circunstâncias ela ocorre. Preocupados com o tema, estudiosos alertam para as dificuldades em mensurar os efeitos das IPs e em demonstrar as cadeias causais quando se busca efeitos remotos e gerais da participação (Gurza Lavalle 2011).

Este artigo nutre-se do diálogo entre essas duas abordagens, mas enfoca a efetividade das instituições participativas por meio da avaliação dos efeitos da participação nos conselhos de assistência social sobre a gestão dessa política na esfera municipal. Em termos metodológicos, a associação relativa (correlação) entre participação e gestão municipal foi analisada a partir de dois índices, o Índice de Efetividade da Participação (IEP) e o Índice de Gestão Municipal (IGM). Construídos considerando-se a literatura da efetividade da participação e a da política de assistência social, os índices se baseiam em dados do Censo SUAS de 2012, conduzido pelo MDS (Ministério do Desenvolvimento Social e Combate à Fome), que cobrem 93\% dos municípios brasileiros. O IEP agrega, num único valor, indicadores da efetividade da participação nos conselhos municipais, expresso em: (1) grau de institucionalização; (2) qualidade da deliberação e (3) qualidade da representação. Cada indicador é então convertido em um subíndice desagregável do índice geral. O IGM, por seu turno, consiste num índice geral correspondente ao desempenho da gestão da política municipal e mensurado por indicadores das capacidades técnico-administrativas, como estrutura administrativa, gestão financeira, gestão dos serviços, bem como programas, projetos e benefícios da assistência social. A análise da relação entre os índices é operacionalizada por meio de um conjunto de variáveis (independentes e dependentes) que será apresentado e explorado adiante.

Neste trabalho apresentamos o desempenho dos municípios brasileiros quanto à efetividade da participação, associada à gestão da política de assistência social. Em consonância com outros estudos, concluímos que a participação importa para a gestão da política. A análise sustenta que a participação nos conselhos de assistência social se relaciona positivamente com os resultados na gestão da política do setor, ainda que outros fatores possam interferir. Em outras palavras, a efetividade da participação é proporcional à efetividade da gestão da política na assistência social.

Além de analisar os efeitos dos conselhos de assistência social sobre o desempenho da política setorial, o artigo perscruta alguns condicionantes ou condições sob os quais a participação importa para a política municipal. Estudiosos dos condicionantes da efetividade da participação defendem uma análise multidimensional que inclua fatores endógenos e exógenos das IPs (Cunha 
${ }^{2}$ Enquanto fatores exógenos, a região e o porte populacional remetem ao contexto da participação, definidos com base em modelos de regressão que previamente compararam sua influência em face de variáveis de controle socioeconômica e partidária. Os testes estatísticos com as variáveis de controle constam no Relatório de Pesquisa (Almeida, Carlos, Silva, 2016b)
2009; Cunha et al., 2011; Petinelli 2013; Zorzal \& Carlos 2017). Definidos como interdependentes, os fatores endógenos consistem na dinâmica de funcionamento interno (desenho institucional, participantes e processo de decisão), ao passo que os exógenos remetem a dimensões "externas" às IPs (contexto histórico, político-partidário e socioeconômico, e o setor da política). Neste trabalho, definimos dois condicionantes a partir dos quais indagamos se a participação importa: região e porte dos municípios ${ }^{2}$. A análise permite observar a efetividade da participação sob dupla condição: do recorte regional e do populacional.

No intuito de alcançar maior precisão no exame da relação entre participação e gestão da política pública, estruturamos o trabalho em três partes. $\mathrm{Na}$ primeira, discutimos os desafios apontados pela literatura acerca da avaliação da efetividade da participação nas políticas públicas. Na segunda, apresentamos, em termos teóricos e metodológicos, os índices construídos para mensurar os efeitos da participação sobre a política de assistência social. Na terceira parte, apresentamos e discutimos os dados da pesquisa em três subseções que se complementam: (1) caracterização geral do IEP e IGM e sua distribuição segundo a região e o porte populacional dos municípios brasileiros; (2) análise da correlação entre os índices por meio de testes estatísticos de regressão linear e agrupamentos de homogeneidade; e (3) discussão das condições sob as quais a participação produz efeitos sobre a gestão da política de assistência social.

\section{Desafios na produção de conhecimento sobre a efetividade da participação}

Em vários dos balanços disponíveis sobre os estudos referentes às IPs, e em especial aos conselhos gestores, encontramos o reconhecimento de que vivemos num "momento de fronteira", particularmente derivado dos desafios de se diagnosticar os efeitos dessas instituições nas políticas públicas.

Para Gurza Lavalle, Voigt e Serafim (2016), por exemplo, se os estudos predominantes, de natureza qualitativa e baseados em estudos de caso, forneceram uma notável compreensão em termos do funcionamento dos conselhos gestores em contextos sociopolíticos específicos e em áreas de políticas públicas distintas, de agora em diante essa agenda estaria desafiada a propor desenhos de pesquisa que permitam maior poder de generalização para o conhecimento produzido. Teríamos herdado, dos estudos anteriores, um rico conhecimento de caráter verticalizado sobre os conselhos, mas precisaríamos, agora, avançar em termos de generalizações, com a proposição de modalidades de formalização e quantificação. Nesse contexto, salienta-se que precisamos avançar a partir de análises comparativas, que contemplem um conjunto mais expressivo de experiências, de modo a entender melhor "quais atributos" dos conselhos determinam a constituição de esferas públicas efetivamente democráticas e qual a própria importância da qualidade da participação para o grau de influência dos conselhos no desempenho das gestões e resultados de políticas públicas.

A bibliografia brasileira vem avançando por essas fronteiras e, como resultado, já temos à disposição vários estudos com desenhos de pesquisas inovadores face ao desafio de diagnosticar os efeitos das IPs. Esses estudos têm fornecido uma preciosa contribuição ao fertilizar a agenda de debate com novas hipóteses de trabalho. Nesse conjunto, merece destaque, por exemplo, a técnica dos pares contrafatuais, que tem permitido a algumas análises sugerirem associações positivas entre IPs e resultados de políticas públicas (Vaz 2011; Pires \& Vaz 2010). Essa técnica consiste, basicamente, na comparação de pares de municípios que apresentam semelhanças em termos de algumas características consideradas relevantes, como as de natureza sociodemográficas e econômicas, mas que se distinguem em termos da existência de IPs. O emprego dessa técnica 
tem permitido avançar não apenas em termos de um referencial de análise comparativa, mas também em termos da diversificação de IPs contempladas num mesmo estudo. Com base nessa técnica, Vaz (2011) analisou as potenciais influências da participação política (medidas pela diversidade, quantidade e longevidade de IPs) na distribuição de bens, serviços públicos e na administração de políticas em oito municípios brasileiros, nas áreas de saneamento, saúde e assistência social. De forma geral, seu estudo constatou que uma maior propensão participativa tende a melhorar os resultados das políticas consideradas.

Para o que nos interessa, vale destacar os resultados encontrados na área de assistência social, inclusive porque, nessa área, o estudo enfocou a relação entre a participação e a capacidade gerencial dos municípios, precisamente o foco da nossa pesquisa. Para todos os munícipios analisados, os dados de Vaz (2011) mostraram que o grau de participação se associou às melhores capacidades, investimento e comprometimento com a política de assistência social por parte de seus gestores públicos.

Entretanto, é importante sublinhar que a técnica de pares contrafatuais permite apenas indicar uma relação de associação entre participação e resultados de políticas públicas. Ao diagnosticar uma associação entre existência de IPs e melhores desempenhos na gestão e nos resultados das políticas, os estudos que adotam essa técnica prestam uma importante contribuição, mas ainda não são conclusivos em termos dos diagnósticos de relações causais. É possível dizer que a maioria dos estudos que vêm inovando a agenda de estudos sobre IPs a partir do foco analítico dos seus efeitos nas políticas têm avançado, sobretudo, no estabelecimento de associações ou em diagnósticos que permitem supor, com maior grau de precisão, a capacidade de influência dessas instituições.

Esse também é o caso do estudo de Gurza Lavalle, Voigt e Serafim (2016), que apresenta um censo da produção decisória dos conselhos municipais de Guarulhos vinculados a diferentes políticas, entre 2005 e 2011. A análise dos padrões decisórios dos conselhos, por meio de suas resoluções, garante um maior grau de precisão para a identificação de impactos dessas instâncias nas suas respectivas áreas, mas ainda não permite a verificação de relações causais.

Vale destacar duas importantes conclusões a que chegou esse estudo. Em primeiro lugar, os autores constataram que há uma produção decisória mais elevada nos conselhos que tenderam à universalização por indução federal e que integram sistemas de políticas, como a assistência social. Em segundo lugar, Gurza Lavalle, Voigt e Serafim (2006) também concluíram que há uma relação entre a longevidade dos conselhos e seus padrões decisórios. De acordo com os resultados, até aproximadamente oito anos de vida, os padrões decisórios dos conselhos restringem-se à própria autorregulação. Após esse período, identificou-se uma maior diversificação dos padrões decisórios dessas instâncias, que passam a incidir de maneira mais efetiva sobre a gestão das suas respectivas políticas, principalmente no caso dos conselhos integrantes de sistemas de políticas públicas que se universalizaram por meio de indução federal. Esse achado permite aventar correções nos diagnósticos produzidos pelas primeiras gerações de estudos sobre os conselhos. Elaborados nos anos iniciais de formação dessas instâncias, tais diagnósticos concluíram, com frequência, pela baixa capacidade de incidência dos conselhos nas suas respectivas políticas.

O trabalho de Silva e Souza (2015), em direção semelhante, também propõe um diagnóstico das capacidades institucionais dos conselhos que sugere um maior poder de influenciar políticas públicas. Para isso, os autores construíram um índice de mensuração dessa capacidade para os conselhos estaduais, utilizando dados da Pesquisa de Informações Básicas Estaduais 2012 (ESTADIC) 
da Fundação Instituto Brasileiro de Geografia e Estatística (IBGE 2013). A pesquisa contemplou as áreas da educação, cultura, esporte, habitação, transporte, saúde, segurança pública, meio ambiente e assistência social. Como indicadores da capacidade institucional, eles consideraram a existência do conselho e de fundos, a realização de reunião nos últimos 12 meses, e determinados atributos dos Conselhos (se paritários, deliberativos ou normativos). É importante destacar que os autores não encontraram uma associação entre, de um lado, posição geográfica e nível econômico dos estados e, de outro, desempenho no índice. Mas, no que diz respeito às áreas, concordando com outros estudos comparativos, os índices foram melhores naquelas em que os conselhos gestores estão inscritos em sistemas nacionais, como saúde e assistência social.

Como foi mencionado, esses estudos representam um avanço em termos de diagnosticar, com maior precisão, os fatores que concorrem para o sucesso das IPs em produzir efeitos sobre as políticas públicas, especialmente contemplando estudos comparativos. Mas ainda não podemos, a partir deles, atestar relações causais. Para isso, é preciso considerar novos desafios.

Em balanço da literatura publicada em inglês e francês sobre o assunto, Abelson e Gauvin (2006) arrolam um conjunto de dificuldades e desafios que se impõem para o conhecimento dos impactos de processos participativos em políticas públicas. Segundo os autores, é preciso, por exemplo, definir o papel crucial das variáveis contextuais na formação e no funcionamento dos processos de participação. Conforme argumentam, geralmente, as análises não distinguem entre os determinantes dos efeitos dos processos participativos e os efeitos propriamente ditos. Ou seja, se por um lado a identificação das condições favoráveis aos processos participativos é uma tarefa fundamental, por outro lado essas condições precisam ser, em alguma medida, distinguidas dos seus efeitos propriamente ditos. Além disso, a própria tarefa de definir o ponto final de um exercício de participação para avaliar sua efetividade é, frequentemente, pouco evidente. Afinal, como mostrou o estudo de Gurza Lavalle, Voigt e Serafim (2016), os impactos de um processo participativo podem demorar a surgir. Além disso, nesse ínterim, um conjunto de outras variáveis podem se interpor, dificultando a possibilidade de atestar relações causais imediatas entre participação e resultados de políticas. Adicionalmente, como argumenta O'Faircheallaigh (2009), geralmente os estudos não abordam como as diferentes facetas dos processos participativos interagem na produção de efeitos. Segundo o autor, pode haver trade-offs entre as dimensões constitutivas da participação que geralmente não são reconhecidas. Assim, o próprio relacionamento entre essas dimensões deve ser objeto de maior atenção para as análises que se preocupam com os efeitos dos processos participativos nas políticas públicas.

O estudo que aqui apresentamos se beneficia dos avanços promovidos pelos trabalhos mais recentes sobre os efeitos das IPs brasileiras na produção de políticas. Para contribuir com esta agenda de pesquisa, examinamos, por meio de um estudo comparado ao nível dos municípios brasileiros, as relações existentes entre participação e gestão de políticas setoriais. Como mencionamos, a avaliação dos efeitos da participação dos conselhos gestores de assistência social nessa política pública se baseia em associações estatísticas entre o Índice de Efetividade da Participação (IEP) e o Índice de Gestão Municipal (IGM). A construção desses dois índices assenta-se no banco de dados do Censo SUAS (2012), cuja seleção das variáveis seguiu indicações da literatura especializada acerca da efetividade da participação e da política de assistência social. Vejamos cada um deles. 


\section{III. Índice de Efetividade da Participação e Índice de Gestão Municipal: marcos teóricos e metodológicos}

Esta seção apresenta as bases teóricas a partir das quais selecionamos as variáveis que compõem o Índice de Efetividade da Participação (IEP) e o Índice de Gestão Municipal (IGM). As variáveis utilizadas na construção desses índices foram selecionadas a partir dos dados do Censo SUAS (2012), conduzido pelo Ministério do Desenvolvimento Social (MDS), que cobrem 5.178 municípios brasileiros (93\% dos municípios). Ao final, uma nota metodológica esclarece os procedimentos técnicos de construção desses dois índices.

Para a seleção das variáveis do IEP, estabelecemos um diálogo, de um lado, com os estudiosos da democracia deliberativa que têm buscado no desenho institucional das IPs os determinantes da "qualidade do processo de deliberação". A forma como se dá a "institucionalização da deliberação", expressa no desenho institucional das IPs é considerada, assim, importante preditora dos efeitos democráticos por elas promovidos (Saward 2000; Faria \& Ribeiro 2011). Nessa direção, buscamos no Censo SUAS aquelas variáveis que pudessem indicar o quanto e como estão institucionalizadas nos conselhos as regras referentes à obtenção de "bens democráticos" como a inclusividade dos cidadãos no processo político, a eficiência na distribuição de poder, a pluralidade e igualdade nos processos de tomada de decisão, a capacidade de proposição pelos atores de novos temas nos processos decisórios, o controle dos participantes sobre as ações públicas etc. (Smith 2009; Almeida \& Cunha 2011; Cunha 2010).

De outro lado, consideramos, na construção do índice, o diálogo com os estudos sobre o fenômeno da pluralização da representação, promovida por instâncias como os conselhos municipais. Tais estudos têm destacado que a qualidade dessas novas formas de representação depende (1) do grau em que as instâncias prestam contas e tornam públicas suas ações para públicos mais amplos, (2) o equilíbrio de poder entre Estado e sociedade civil e (3) o controle dos representantes pelos representados (Gurza Lavalle \& Isunza Vera 2011; Gurza Lavalle, Houtzager \& Castelo 2006; Lüchmann 2007; 2011; Avritzer 2007; Almeida 2010). Orientados por esses estudos, que argumentam que a legitimidade da representação exercida nas IPs depende do seu grau de enraizamento na sociedade, buscamos no Censo SUAS aquelas variáveis que pudessem indicar a capacidade de os conselhos prestarem contas de suas ações e se conectarem a públicos mais amplos, bem como garantirem a paridade entre sociedade civil e Estado na sua dinâmica de funcionamento. Além disso, procuramos verificar também variáveis indicadoras do grau de controle da sociedade civil sobre sua própria representação no conselho, medida, por exemplo, pela forma de escolha do representante.

Com base nesse diálogo, o IEP foi composto por três subíndices, denominados: Nível Institucionalização (N1), Nível Deliberação (N2) e Nível Representação $(\mathrm{N} 3)^{3}$.

O Nível Institucionalização (N1) mede o grau de institucionalização e as condições de infraestrutura dos conselhos, mensurado por variáveis que indicam: (1) o grau de formalização de suas regras de funcionamento; (2) os recursos que possuem para cumprir as exigências da burocracia de gestão das políticas públicas (Lima et al., 2014); (3) o grau em que o conselho é reconhecido formalmente como integrante da rede estatal de produção e controle das políticas públicas (Lima et al., 2014). Conforme acentua a literatura, referindo-se aos conselhos, quanto "maior a regulamentação sobre o funcionamento, mais institucionalizados são esses espaços" (Faria \& Ribeiro 2011, p.128). Quanto mais formalizadas a regras, mais chances o funcionamento dos conselhos tem de ser produto de decisões discutidas e acordadas previamente, 
obedecendo aos princípios do "universalismo de procedimentos" e não de correlações de forças contextuais. Além disso, o grau de institucionalização das IPs depende de seu enraizamento institucional, que pode ser medido pela força contida no seu ato normativo de criação e na sua longevidade. Como vimos, a longevidade também tem sido associada à capacidade das IPs de lidarem com a burocracia estatal e de influir o processo decisório (Gurza Lavalle, Voigt \& Serafim 2016; Lima et al., 2014). Assim, nesse subíndice, o IEP se fundamenta em "variáveis do enraizamento institucional dessas instâncias, do seu reconhecimento como parte da rede estatal de controle e produção de políticas, do seu acúmulo de conhecimento organizacional, dos recursos humanos e materiais que garantem que desempenhem suas funções" (Almeida, Carlos \& Silva 2016a, p.256).

O Nível Deliberação (N2), por sua vez, foi constituído por variáveis que indicam a qualidade das condições de deliberação dos conselhos e a amplitude de suas decisões na política do município. Nesse indicador, a deliberação é medida: (1) pela capacidade de incidência do conselho na política de assistência social; (2) pelas condições institucionais que balizam o processo decisório, ou seja, a existência de planejamento, rotinas e regras prévias acerca dos assuntos que devem ser objeto de deliberação dos conselhos, assim como a estrutura organizativa dos conselhos para a deliberação; (3) pela capacidade de obter "audiência pública no Estado", no que concerne ao poder de ativar as conexões com o seu entorno político-institucional, como uma das condições que afeta as possibilidades de o conselho influenciar a política pública (Almeida \& Tatagiba 2012). Em suma, as variáveis que compõem o N2 são indicadoras "do grau de deliberação a partir dos procedimentos ou condições que orientam a tomada de decisão; da incidência concreta dos conselhos na política de assistência social; e das conexões ativas que essas instâncias mantêm com o seu entorno institucional" (Almeida, Carlos \& Silva 2016a, p.257).

Por fim, o Nível Representação (N3) foi composto por variáveis indicadoras do grau de representatividade dos conselhos e do quanto essas instâncias prestam contas e tornam públicas suas ações. Avalia, nesses termos: (1) a igualdade entre a representação governamental e a sociedade civil; (2) o controle da representação da sociedade civil por suas suas organizações; (3) a ancoragem societária dos conselhos; (4) a prestação de contas e divulgação de seus atos a públicos mais amplos (Almeida, Carlos \& Silva 2016a, p.259) ${ }^{4}$.

${ }^{4}$ No Apêndice apresentamos os Quadros 1, 2 e 3, com as variáveis que compõem os três níveis do IEP, bem como os respectivos pesos atribuídos a cada uma delas. Estes últimos também estabelecidos com base nas predições da literatura acerca das variáveis relevantes da qualidade da participação.
O outro índice aqui utilizado, o IGM, é composto por indicadores que possibilitam mensurar as "capacidades estatais" ou técnico-administrativas dos municípios em implementarem a política de assistência social, aspecto relevante na avaliação da efetividade da política pública, conforme os analistas têm indicado (Pires \& Vaz 2015). Desse modo, foi com base nos estudos acerca da política de assistência social e dos desafios para sua concretização que construímos o Índice de Gestão Municipal (IGM).

Por meio desse índice, buscamos avaliar a qualidade da gestão municipal nesse setor de política, considerando a estrutura institucional, a oferta de serviços e benefícios para a população-alvo e a estrutura de recursos humanos das administrações municipais na assistência social. Somente com a LOAS (Lei Orgânica da Assistência Social), em 1993, a inscrição da assistência social como área de política específica foi regulamentada e, desde então, um conjunto de normativas foram construídas para definir os usuários dessa política e os direitos a ela correlatos, os princípios e instrumentos para sua gestão e sua estruturação no território nacional. Com efeito, em 2004, o Conselho Nacional de Assistência Social aprovou a Política Nacional de Assistência Social (PNAS) e, em 2005, a Norma Operacional Básica do SUAS (NOB/SUAS), que detalha e 
5 A "proteção social" é orientada pelo princípio da integralidade, que prevê a sua oferta em completude. A PNAS define dois níveis de proteção: a básica, de caráter preventivo diante do diagnóstico de situações de vulnerabilidade e risco, e a especial, de alta e média complexidade, de caráter reparador. Esta última atua onde os indivíduos e famílias já tiveram seus direitos violados (Couto 2009).
${ }^{6} \mathrm{O}$ Quadro 4, no Apêndice, apresenta as variáveis correspondentes na definição do IGM. disciplina a gestão da política de assistência, distribuindo suas responsabilidades e definindo suas instâncias e instrumentos de gestão.

O modelo de proteção social ${ }^{5}$ do SUAS (Sistema Único da Assistência Social) baseia-se em cinco princípios: (1) é uma política de direitos que opera serviços e benefícios; (2) tem um caráter federalista, na qual os entes atuam integradamente com responsabilidades definidas; (3) opera por meio de um sistema único; (4) combina o processo de gestão com os sistemas de participação e controle social; (5) é baseada num modelo pactuado entre os entes federativos por meio de instâncias colegiadas, como as Comissões Intergestores Bipartites (CIBs), com representantes das esferas estadual e municipal, e as Comissões Intergestores Tripartes (CITs), que contam com a área federal (Sposati 2009). O SUAS está assentado no princípio da descentralização política e da participação social, que transfere prerrogativas e competências a esferas intermediárias e locais e prevê instâncias obrigatórias de controle social, os conselhos gestores da área. A estruturação dessa política como um sistema pressupõe que suas ações sejam organizadas de forma planejada, contínua e sistemática, por meio de uma rede constituída e integrada, com padrões de atendimento qualificados e pactuados (Couto 2009).

A consolidação do modelo de proteção social desenhado pelo SUAS depende, assim, de mudanças político-institucionais e culturais de grande envergadura. Segundo Sposati (2009), são mudanças que exigem: (1) o exercício racional de uma gestão estatal orientada pelos princípios dos direitos e da cidadania; (2) a instituição de ações planejadas e orientadas não apenas para agir em situações já caracterizadas pela desproteção, mas para a prevenção dessas situações; (3) o rompimento com modelos autoritários de gestão, onde a assistência é vista restritamente como a "face humana do governante"; (4) a instituição de uma gestão democrática, pública, que opera diretamente ou em parcerias.

Outrossim, a concretização desse modelo exige um esforço contínuo para qualificar os profissionais para operar o sistema e, portanto, exige romper com "a lógica voluntarista e de senso comum que tem alocado recursos humanos nos serviços sociais" (Couto 2009, p.216). O investimento na qualificação dos profissionais da área tem sido visto, assim, como um "fator estratégico, fundamental para materializar as metas de efetivação das políticas públicas na área social" (Ananias 2009, p.7).

O Índice de Gestão Municipal (IGM) aplicado à política de assistência social visa a mensuração da qualidade da gestão nesse setor, com base nos aspectos apontados pela literatura especializada como "dilemáticos" à sua concretização como política pública. Neste sentido, o IGM é composto por quatro dimensões, e suas respectivas variáveis: (1) estrutura institucional da gestão municipal: (1a) grau de complexidade e de institucionalização administrativa da gestão, no que tange ao grau em que a gestão está organizada para produzir indicadores, diagnósticos e informações para planejar ações; (1b) ao grau de articulação da gestão com outros órgãos da rede estatal envolvida na produção e no controle da política pública; (2) estrutura de oferta de serviços e benefícios socioassistenciais: contempla a quantidade e a variedade de serviços e benefícios para os quais a gestão se organiza para ofertar, de acordo com o que estabelece a PNAS; (3) estrutura de recursos humanos: se refere à quantidade, à qualificação e ao tipo de vínculo empregatício dos trabalhadores disponíveis para a gestão da política de assistência social e para os serviços e unidades de atendimento aos usuários; (4) envolvimento da política de assistência social com as ações de inclusão produtiva e geração de trabalho e renda ${ }^{6}$.

Para a construção dos dois índices, atribuímos pesos distintos à cada variável. As variáveis foram selecionadas de acordo com sua importância como 


\section{III.1. Nota metodológica}

\footnotetext{
${ }^{7}$ Existem dois critérios para leitura do valor desta medida estatística: um rígido, onde o $\alpha$ é pelo menos 0,700 , e outro um pouco menos rígido, onde o $\alpha$ é pelo menos 0,600 (Maroco \& Garcia-Marques 2006). Como dispomos de um fenômeno multifacetal, optamos pelo critério menos exigente: nível $1 \propto 0,632$; nível $2 \alpha 0,632$; IEP geral $\alpha$ 0,692 . Quanto ao IGM, obtivemos $\alpha 0,641$.

${ }^{8}$ Essa ponderação se fez necessária já que a teoria confere importância diferente às variáveis, a depender da característica que ela quantifica.
}

indicadoras da efetividade da participação e da qualidade da gestão. A definição do grau de importância foi estabelecida no diálogo com a literatura especializada, mencionada anteriormente.
Os índices utilizados são enquadrados como índices sintéticos e reúnem diversas características de um determinado fenômeno em um valor que, neste caso, varia de 0 a 1 . As unidades de análises são os municípios brasileiros.

Conforme mencionado, o Índice de Efetividade da Participação foi produzido a partir de três subíndices: N1 (Institucionalização), N2 (Deliberação) e N3 (Representação), respectivamente: (1) grau de institucionalização e condições de infraestrutura dos conselhos; (2) grau e condições de deliberação dos conselhos; (3) grau de representatividade/publicidade dos conselhos. Aglutinados, formam um índice sintético, o IEP Geral. Para o IGM (Índice de Gestão Municipal), na seleção das variáveis foram contempladas quatro dimensões: (1) gestão municipal; (2) serviços e benefícios socioassistenciais; (3) recursos humanos; (4) ações de inclusão produtiva e geração de trabalho e renda.

As variáveis componentes dos dois índices foram submetidas ao teste de consistência interna denominado alpha de Cronbach ${ }^{7}$. Devido a essa exigência estatística, o IGM ficou estruturado apenas em um índice geral, diferente do IEP que possibilitou a criação de três subíndices e o índice geral. $\mathrm{O}$ passo seguinte foi padronizar as escalas de cada variável, enquadrando-as na escala desejada, conforme a fórmula abaixo:

$$
\frac{\text { (Valor Observado - Menor Valor da Distribuição) }}{\text { (Maior Valor da Distribuição - Menor Valor da Distribuição) }}
$$

Como resultado, as variáveis ficaram com valores que variam de 0 a 1 . Quanto mais próximo de 1, melhor é o desempenho do município em uma dada variável. Para o caso do IGM, fez-se uma média simples, gerando um valor único para cada município, sintetizando as informações oriundas das 46 variáveis. Para o IEP, fez-se uma média ponderada ${ }^{8}$ em cada nível, gerando os três subíndices para cada município. Por fim, operacionalizou-se uma média simples com os três subíndices, N1, N2 e N3, gerando o IEP Geral por município.

Finalmente, cabe esclarecer que, para fins de análise, os índices foram categorizados em classes de intensidade, considerando os intervalos baixo, médio e alto 9 .

\section{Efetividade das instituições participativas na gestão da política de assistência social}

Nesta seção, apresentamos a caracterização geral do IEP e do IGM a partir de sua distribuição no país, por região e por porte populacional de município. Posteriormente, seguem os testes de correlação entre esses dois índices, que demonstram a associação relativa entre a efetividade da participação e o desempenho da gestão da política de assistência social nos municípios do país. Por fim, discute-se alguns condicionantes ou condições sob as quais a efetividade das IPs gera resultados sobre a gestão da política de assistência social nos municípios.

\section{IV.1. Caracterização geral do IEP e IGM}

A observação geral do desempenho dos municípios segundo a região geográfica e o porte populacional da municipalidade aponta para variações significativas nos índices. Em outras palavras, a caracterização do IEP e do IGM nos 
Tabela 1 - IEP x IGM segundo a região geográfica e o porte do município

\begin{tabular}{|c|c|c|c|c|c|c|c|c|c|c|c|}
\hline \multirow[t]{2}{*}{ Porte } & \multirow[t]{2}{*}{ Estatísticas } & \multicolumn{2}{|c|}{ Norte } & \multicolumn{2}{|c|}{ Nordeste } & \multicolumn{2}{|c|}{ Sudeste } & \multicolumn{2}{|c|}{ Sul } & \multicolumn{2}{|c|}{ Centro-Oeste } \\
\hline & & IEP & IGM & IEP & IGM & IEP & IGM & IEP & IGM & IEP & IGM \\
\hline \multirow[t]{2}{*}{ Pequeno I } & Média & 0,356 & 0,412 & 0,398 & 0,420 & 0,385 & 0,402 & 0,409 & 0,425 & 0,390 & 0,425 \\
\hline & Desvio Padrão & 0,159 & 0,123 & 0,141 & 0,111 & 0,138 & 0,125 & 0,141 & 0,123 & 0,145 & 0,118 \\
\hline \multirow[t]{2}{*}{ Pequeno II } & Média & 0,414 & 0,462 & 0,428 & 0,492 & 0,449 & 0,516 & 0,476 & 0,529 & 0,496 & 0,555 \\
\hline & Desvio Padrão & 0,147 & 0,123 & 0,140 & 0,108 & 0,136 & 0,113 & 0,138 & 0,119 & 0,146 & 0,112 \\
\hline \multirow[t]{2}{*}{ Médio } & Média & 0,413 & 0,528 & 0,489 & 0,537 & 0,497 & 0,575 & 0,533 & 0,596 & 0,481 & 0,542 \\
\hline & Desvio Padrão & 0,111 & 0,095 & 0,141 & 0,097 & 0,131 & 0,110 & 0,132 & 0,116 & 0,136 & 0,085 \\
\hline \multirow[t]{2}{*}{ Grande } & Média & 0,556 & 0,567 & 0,554 & 0,616 & 0,566 & 0,614 & 0,565 & 0,616 & 0,544 & 0,623 \\
\hline & Desvio Padrão & 0,112 & 0,100 & 0,132 & 0,108 & 0,124 & 0,121 & 0,133 & 0,122 & 0,111 & 0,116 \\
\hline \multirow[t]{2}{*}{ Metrópole } & Média & 0,527 & 0,700 & 0,659 & 0,774 & 0,706 & 0,720 & 0,600 & 0,779 & 0,665 & 0,812 \\
\hline & Desvio Padrão & 0,060 & 0,074 & 0,138 & 0,067 & 0,097 & 0,080 & 0,076 & 0,129 & 0,005 & 0,136 \\
\hline \multirow[t]{2}{*}{ Total } & Média & 0,385 & 0,443 & 0,417 & 0,452 & 0,421 & 0,452 & 0,430 & 0,454 & 0,415 & 0,457 \\
\hline & Desvio Padrão & 0,156 & 0,128 & 0,145 & 0,120 & 0,148 & 0,143 & 0,146 & 0,136 & 0,152 & 0,132 \\
\hline
\end{tabular}

Fonte: Elaborado pelos autores, a partir do Censo SUAS (2012).

9 Para os dois índices utilizados, consideramos como baixa intensidade o valor que atingiu até 0,33 ; média intensidade, quando variou de 0,34 a 0,66 ; e alta intensidade, quando apresentou valores maiores de 0,67. Esse intervalo seguiu a proposta de Pires e Vaz (2010) para analisar o grau de institucionalização das instituições participativas.

${ }^{10}$ O porte do município é definido conforme sua população. Metrópole (acima de 900.000), Grande Porte (100.001 a 900.000), Médio Porte (50.001 a 100.000), Pequeno Porte II (20.001 a $50.000)$ e Pequeno Porte I (até 20.000). Fonte: PNUD (2013). municípios do país evidencia desigualdades expressivas, ora marcadas pelo recorte regional, ora pelo populacional. A Tabela 1 demonstra como varia a performance dos índices nesses dois quesitos.

Considerando-se a Tabela 1, a primeira constatação de relevo diz respeito ao desempenho da região Norte em ambos os índices, a única a obter médias abaixo das médias nacionais, 0,385 e 0,443, para o IEP e IGM, respectivamente. Já no Nordeste e Centro-Oeste, os valores do IEP não se distanciaram muito da média nacional $(0,417$ e 0,415 , respectivamente). Nessas regiões, o IGM ficou próximo à média nacional no Nordeste $(0,452)$ e acima dela no Centro-Oeste $(0,457)$.

Em relação às outras duas regiões, Sudeste e Sul, a situação é mais positiva. O IEP de ambas está acima da média: o Sudeste com 0,421 e o Sul se destacando com 0,430. Quanto ao IGM, o Sudeste apresentou desempenho igual à média nacional e o Sul levemente acima, com 0,454. Considerando-se as desigualdades internas à cada região, em relação ao IEP, a Norte apresentou uma desigualdade maior entre os seus municípios, com desvio padrão de 0,156, levando-se a concluir que, além de um baixo desempenho, existe uma heterogeneidade entre seus municípios quanto à efetividade da participação nos conselhos gestores. Em relação ao IGM, o Sudeste apresentou uma desigualdade maior entre os seus municípios, apresentando desvio padrão de 0,143 . No âmbito nacional, o que se pode observar é que os municípios são mais desiguais no tocante à efetividade da participação quando comparados ao desempenho de suas gestões municipais na política de assistência social.

Por seu turno, a distribuição dos índices por porte populacional demonstra significativa variação nesse agregado ${ }^{10}$. A classificação do IEP e do IGM por porte de município aponta uma tendência ascendente, conforme mostra a Tabela 1. O pior desempenho é observado nos municípios de porte pequeno I, com média abaixo da nacional, seguido, em ordem crescente, pelos demais portes. Destacam-se, assim, aqueles de porte Grande e Metrópole, com IEP de 0,563 e 0,654, respectivamente, e IGM de 0,680 e 0,840, respectivamente. De modo geral, o IEP e o IGM aumentam na medida em que aumenta o porte populacional dos municípios brasileiros. Em outras palavras, quanto maior o porte populacional, melhor o desempenho. 
${ }^{11}$ Nesse caso, a única exceção ocorre nas metrópoles das regiões Sul e Centro-Oeste, pois apontam maior heterogeneidade no IGM, apenas.
Em complemento, considerando-se o desempenho médio dos munícipios nos índices, a tabela cruzada entre o porte populacional, na linha, e a região geográfica, na coluna, permite constatar uma variação no desempenho e uma heterogeneidade interna em cada célula do cruzamento. Ou seja, há uma variação externa, entre regiões/portes cruzados, e interna, entre os municípios de um mesmo segmento do cruzamento.

O desempenho do IEP e do IGM, assim, varia de acordo com a distribuição territorial e o porte populacional dos municípios brasileiros. Os cruzamentos confirmam a região Norte como a de pior desempenho nos dois índices, seja na média geral, seja na sua distribuição por portes de municípios. Por sua vez, as regiões Sul e Sudeste alçaram o melhor desempenho, se destacando na média geral e em todos os recortes populacionais.

A desigualdade no interior das regiões e portes, medida pelo desvio padrão, atesta a heterogeneidade intra-regional em todos os recortes populacionais dos municípios, sendo mais agravada na região Norte, em relação ao IEP. Porém, quanto ao IGM, é a região Sudeste que apresenta a maior heterogeneidade. Ainda neste quesito, em todas as regiões ${ }^{11}$, encontramos maior diferenciação interna nos municípios de porte pequeno I, quer no índice de efetividade da participação, quer no de gestão da política. Desse modo, o município pequeno I, além de apresentar pior desempenho em ambos os índices, é o de maior desigualdade interna. Por seu turno, comparativamente ao IGM, o índice de maior heterogeneidade é o IEP, cujo desvio padrão é superior em todas as regiões. O Índice de Gestão Municipal, sendo internamente mais homogêneo, tem na região Sudeste aquela de maior desigualdade.

\section{IV.2. A efetividade da participação importa para a qualidade da gestão?}

${ }^{12}$ Segundo as classes de intensidade, especificadas na nota 8 , a grande maioria dos municípios está classificada na categoria média, em ambos os índices, seguido pela categoria baixo e, depois, alta.

Verifica-se uma performance
A correlação entre o Índice de Efetividade da Participação e o Índice de Gestão da Política de Assistência Social nos municípios brasileiros é aqui atestada por meio de testes estatísticos de regressão linear e agrupamentos de homogeneidade. A expectativa teórica era de que os dois índices estabelecessem uma relação linear e proporcional. Conforme mostra o diagrama de dispersão, no Gráfico 1, tal pressuposição foi atendida. Portanto, encontramos entre os índices uma relação linear e proporcional, cuja inclinação da trajetória é ascendente. Buscando quantificar essa relação, fez-se uma correlação com o R de Pearson. O valor encontrado para o teste foi de 0,496 , o que sugere uma associação de média intensidade, que será melhor escrutinada com testes estatísticos mais precisos.

Para refinar o entendimento acerca desta associação relativa entre os índices, foi usado um tipo de análise multivariada chamada de correspondência múltipla ou homogeneidade (HOMALS). A partir de valores qui-quadrado, o teste reduz as dimensões dos dados a um plano bidimensional, aproximando as categorias de cada variável que possuam associação. Assim, em cada quadrante ficam as categorias mais próximas, formando grupos relativamente homogêneos.

Como podemos observar no Gráfico 2, as variáveis responsáveis pela distribuição dos municípios foram: no eixo X (Dimensão 1), os dois índices, IEP e IGM, segundo os intervalos de intensidade ${ }^{12}$, e no eixo Y (Dimensão 2), o porte do município. Assim, as regiões foram alocadas segundo sua proximidade com o desempenho dos índices por classes de intensidade, formando os grupos. $\mathrm{Na}$ horizontal do gráfico, temos, à direita, as categorias do IEP e IGM que indicam alto desempenho e, no lado oposto, à esquerda, as de baixo desempenho. Na vertical, temos, na parte inferior do gráfico, as metrópoles e os municípios de grande porte e, no lado oposto, parte superior, os pequenos e médios. 
melhor dos municípios no IGM em comparação ao IEP com menos municípios classificados em baixo e mais em médio e alta intensidade.
Gráfico 1 - Gráfico de dispersão IGM x IEP

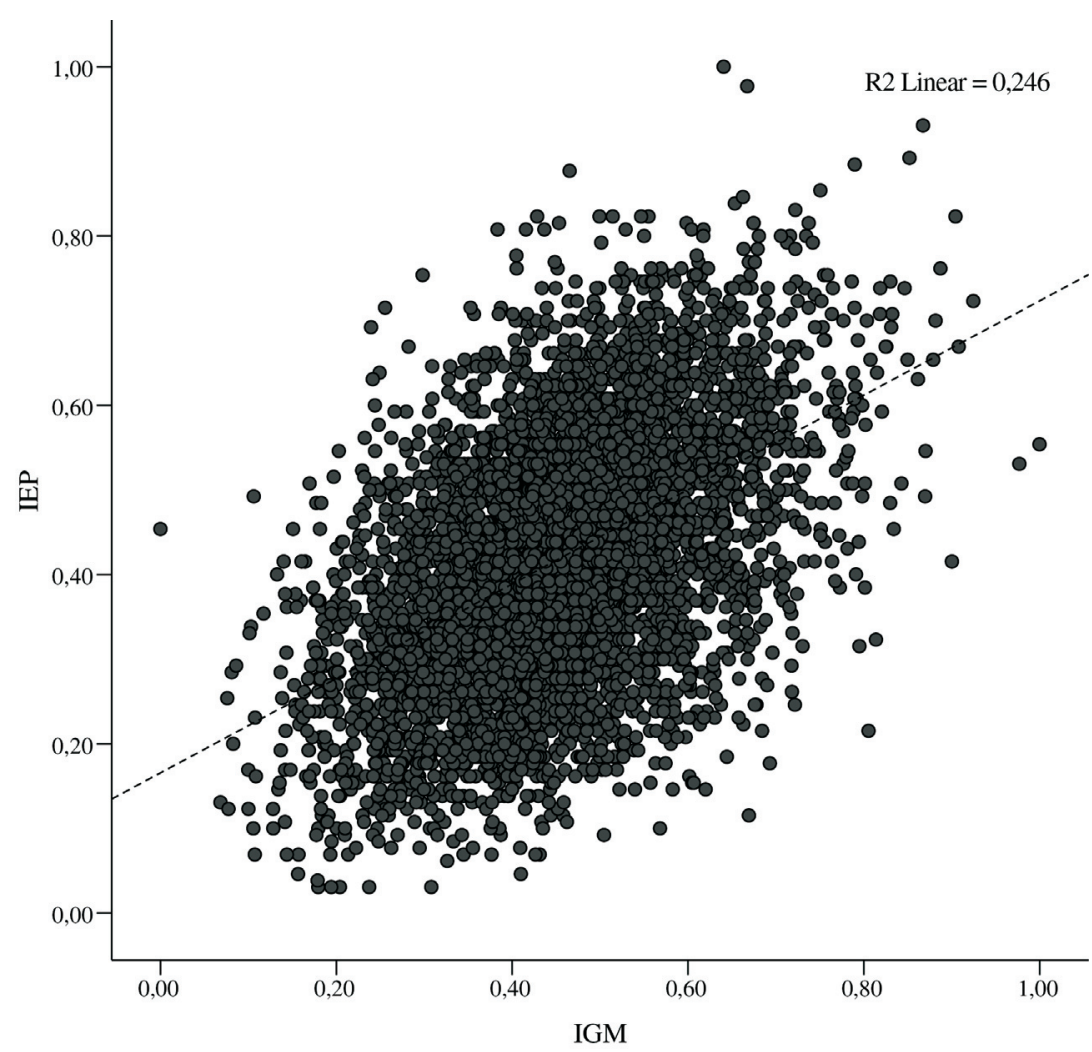

Fonte: Elaborado pelos autores, a partir do Censo SUAS (2012).

Gráfico 2 - Análise de Homogeneidade (IEP, IGM, Porte e Região)

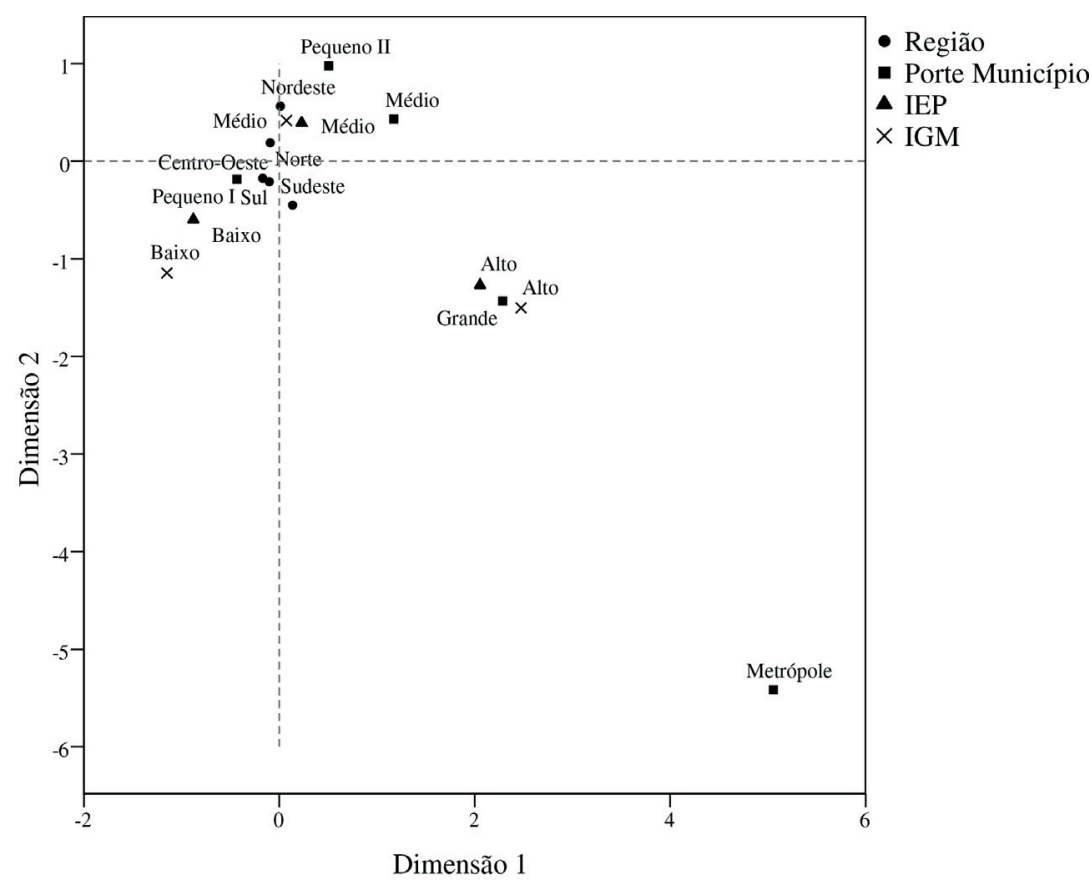

Fonte: Elaborado pelos autores, a partir do Censo SUAS (2012). 
Observando os grupos formados, identificamos quatro situações:

I. Quadrante direito superior: grupamento formado pelos municípios médio e pequeno II, com desempenhos "Médio" no IEP e IGM, e a região Nordeste;

II. Quadrante direito inferior: grupamento formado pelos municípios grandes, as metrópoles, as categorias "Alto" para os dois índices, e a região Sudeste;

III. Quadrante esquerdo inferior: os municípios com baixo desempenho no IEP e IGM, de pequeno porte I, e os municípios das regiões Sul e Centro-Oeste;

IV. No quadrante esquerdo superior: encontra-se solitariamente a região Norte.

Em relação aos dois índices, observamos que as mesmas categorias de desempenho aparecem nos mesmos quadrantes (p. ex., baixo IEP junto com baixo IGM). Essa indicação é reforçada quando rodamos um R de Pearson com os índices contínuos, obtendo coeficiente de 0,496, a um nível extremamente exigente de significância (sig. 0,000). Esta análise estatística complementar reforça o pressuposto teórico acerca da incidência relativa da participação sobre a gestão da política, corroborando a indicação de correlação entre os índices.

Adicionalmente, destacamos do Gráfico 2 os três grupos homogêneos: (a) dos municípios grandes, metrópoles e localizados na região Sudeste com alto desempenho nos índices, (b) dos municípios médios e pequenos II, localizados na região Nordeste e com o desempenho médio nos dois índices e (c) aqueles com os municípios pequeno I, localizados nas regiões Sul e Centro-Oeste, com baixo desempenho nos índices.

No primeiro caso, a análise de homogeneidade atesta que o alto desempenho do IEP e do IGM se concentra nos municípios de população grande e metrópole e na região Sudeste. Esse achado aponta que o contexto do Sudeste e de grande fluxo populacional nos grandes centros urbanos favorece o desempenho dos índices, os quais estabelecem entre si uma trajetória de relação ascendente (o aumento de um implica a elevação do outro) ${ }^{13}$. No segundo, o médio resultado dos índices se aplica aos municípios de população médio, pequeno II e na região Nordeste $^{14}$. Tais dados são coerentes com a assertiva de relação direta entre performance dos índices e porte populacional, sendo esperado maior índice nos municípios de maior porte. Porém, o terceiro grupo, composto por munícipios pequeno I, regiões Sul e Centro-oeste, com baixo desempenho nos dois índices, traz um dado não esperado de acordo com a tendência anterior observada. Talvez a presença do Sul e do Centro-Oeste neste grupo se dê pelo fato de que os municípios pequeno I perfazem $78,4 \%$ e $77,7 \%$ do total de municípios de cada uma dessas regiões respectivamente.

Incógnita maior diz respeito à região Norte, que ficou isolada em um quadrante. Com base nos dados de que dispomos, não é possível fornecer uma explicação de caráter permanente. Mas podemos indicar alguns elementos para a sua compreensão nos remetendo à Tabela 1, que apresenta o desempenho dos municípios no IEP e IGM. A primeira característica que frisamos é a heterogeneidade entre os municípios da região Norte. Essa é maior no desempenho do IEP e se acentua quando observamos os municípios pequenos I e II. Já para o IGM, comparando com as outras regiões, o Norte não apresenta a mesma heterogeneidade anteriormente constatada, embora, nos municípios pequenos I e II, permaneça a maior heterogeneidade. Ou seja, o isolamento da região Norte no Gráfico 1 pode ser explicado pela maior heterogeneidade que seus municípios apresentam em termos do desempenho nos índices, nos portes indicados. 
Além disso, observamos, comparativamente, que na região Norte há certo descompasso entre os índices, ou seja, não se repete o mesmo padrão de relação linear e proporcional observada no restante das regiões (ver Tabela 2). Comparando as categorias de desempenho "Baixo" dos dois índices, no IEP o percentual de municípios que se enquadra nela é $18 \%$ maior que no IGM, enquanto nas categorias de desempenho "Médio", temos, no IGM, 17\% a mais de municípios do que na mesma categoria do IEP. Considerado-se a mesma comparação, porém segmentando por porte de municípios, constatamos que nos municípios pequeno I temos os seguintes resultados: $20 \%$ a mais de município com baixo desempenho no IEP, quando comparado à mesma categoria no IGM. Na categoria "Média", a diferença é maior, no IGM temos 22\% a mais de municípios que no IEP, considerando a mesma categoria de desempenho. Além disso, o porte pequeno I abriga 60,8\% dos municípios da Região. Diante deste exposto, nossa sugestão é a de que a maior heterogeneidade da região Norte no desempenho dos índices e o descompasso existente entre eles podem ter contribuído para que ela ficasse em um quadrante isolado, já que não observamos essa situação nos outros segmentos por porte e região.

Cumpre notar que, analisando as médias de idade dos conselhos de assistência social por porte e pela região dos municípios, constatamos que é também a região Norte a que apresenta a menor média de idade, 12,6 anos, e uma das maiores heterogeneidades neste quesito, mensuradas pelo desvio padrão. Nos municípios pequenos I desta região, em que constatamos o maior descompasso entre IEP e IGM, observamos a menor média de idade dos conselhos, 11,9 anos, e a maior heterogeneidade de todos os contextos envolvidos no comparativo. Assim, podemos sugerir, em concordância com Gurza Lavalle, Voigt e Serafim (2016), a procedência da relação entre a longevidade dos conselhos e sua capacidade de incidência na política. Outra informação que sustenta essa conclusão provém de um modelo de regressão linear, onde o IGM é a variável dependente e a longevidade é o preditor. A idade do conselho explica $1 \%$ da variação do IGM, e a adição de um ano de vida no conselho implica um incremento de 0,002 no IGM. Apesar das estatísticas serem bem modestas, acenam na mesma direção da assertiva a correlação entre o ciclo de vida dos conselhos e sua capacidade de incidência na política pública.

Em suma, a análise da relação entre IEP e IGM demonstra uma tendência linear e proporcional entre os índices, indicando que a efetividade das instituições participativas produz efeitos positivos sobre a gestão da política de assistência social. Não obstante, aponta para alguns condicionantes, como a região e o porte populacional dos municípios, além da longevidade dos conselhos.

Tabela 2 - IEP x IGM segundo o porte do município, a classe de intensidade dos índices e a região Norte

\begin{tabular}{lccccccc}
\hline \multirow{2}{*}{ Porte } & \multicolumn{3}{c}{ IEP } & & & \multicolumn{3}{c}{ IGM } \\
\cline { 2 - 5 } \cline { 7 - 8 } & Baixo & Médio & Alto & & Baixo & Médio & Alto \\
\hline Pequeno I & $47 \%$ & $49 \%$ & $3 \%$ & & $27 \%$ & $71 \%$ & $2 \%$ \\
Pequeno II & $27 \%$ & $67 \%$ & $6 \%$ & & $12 \%$ & $82 \%$ & $6 \%$ \\
Médio & $22 \%$ & $76 \%$ & $3 \%$ & & $2 \%$ & $86 \%$ & $12 \%$ \\
Grande & $0 \%$ & $82 \%$ & $18 \%$ & & $0 \%$ & $78 \%$ & $22 \%$ \\
Metrópole & $0 \%$ & $100 \%$ & $0 \%$ & & $0 \%$ & $50 \%$ & $50 \%$ \\
Total Norte & $38 \%$ & $58 \%$ & $4 \%$ & & $20 \%$ & $75 \%$ & $5 \%$ \\
\hline
\end{tabular}

Fonte: Elaborado pelos autores, a partir do Censo SUAS (2012). 
Tabela 3 - Regressão linear simples, segundo o porte populacional

\begin{tabular}{llcccc}
\hline Porte & & B & Beta & Sig. & R Square \\
\hline Pequeno I & IEP & 0,375 & 0,450 & 0,000 & $20 \%$ \\
Pequeno II & IEP & 0,306 & 0,377 & 0,000 & $14 \%$ \\
Médio & IEP & 0,220 & 0,283 & 0,000 & $8 \%$ \\
Grande & IEP & 0,332 & 0,356 & 0,000 & $12 \%$ \\
\hline
\end{tabular}

Fonte: Elaborado pelos autores, a partir do Censo SUAS (2012).

IV.3. Sob quais condições a efetividade da participação importa para a qualidade da gestão?

Neste estudo, fica patente a importância do porte populacional na relação entre IEP e IGM. No intuito de aprofundar a compreensão acerca dos condicionantes ou condições sob as quais a efetividade das IPs importa para a gestão da política pública, avancemos na verificação sobre o quanto um índice explica o outro em cada porte de municípios. Para averiguar isso, rodamos um modelo de regressão linear simples para cada porte populacional, onde o IGM assume o papel de variável dependente e o IEP de variável independente, pressupondo a seguinte relação: IEP $\rightarrow$ IGM, conforme a Tabela 3 .

Os resultados mostram que há diferentes percentuais de explicação ( $R$ quadrado) para a variação da nossa variável dependente (IGM) em relação ao nosso preditor (IEP), bem como distintos coeficientes parciais (B). O primeiro destaque a ser feito é quanto ao R quadrado de cada modelo. Nessa direção, cumpre notar que nos municípios pequeno I, $20 \%$ da variação do IGM é explicada pelo IEP, seguido pelos municípios de Pequeno Porte II, que registram um percentual de $14 \%$ da variação do IGM explicada pelo IEP. Nos municípios grandes esse percentual é de $12 \%$ e, nos médios, de $8 \%$. Ou seja, nos municípios pequenos a efetividade dos conselhos explica uma parcela maior do desempenho governamental da política em questão, principalmente se considerarmos o percentual explicativo nos municípios pequenos I. Isso significa que, quanto menor o porte populacional do município mais a qualidade da gestão na política de assistência social está associada à efetividade dos conselhos gestores; ao passo que, nos municípios de médio e grande porte, a gestão municipal é menos condicionada à qualidade da participação.

Na sequência, vamos à terceira coluna da Tabela 3 , a do coeficiente parcial (B), que indica o quanto a variação positiva no preditor (IEP) acarretará de mudança no valor do IGM. Novamente, o primeiro destaque vai para os municípios de porte pequeno I, onde a variação positiva no IEP impacta a elevação do IGM em 0,375. Nos municípios grandes, esse impacto é de 0,332, enquanto nos pequenos II, de 0,306, e nos municípios médios, de 0,220. A grande ausência foram as metrópoles. Isso se deu pelo fato de seu modelo não ter alcançado a significância. $\mathrm{O}$ fator determinante para isso é o universo, que, com base nos dados do Censo 2010, é de um total de 17 metrópoles. Apesar de não ser permitido tecer conclusões acerca das metrópoles, nossa sugestão é que as capacidades estatais e complexidades administrativas nelas presentes conferem dinâmicas distintas às disputas políticas e de interesses, reduzindo a incidência dos conselhos sobre a gestão da política, o que não pode ser entendido como a perda de importância deste.

Para sintetizar, os efeitos positivos no IGM, acarretados pela variação também positiva no IEP, são mais fortes nos municípios pequenos I, grandes, pequenos II e médios (conforme o coeficiente parcial B). Logo, as melhorias na gestão da política de assistência social estão mais condicionadas à efetividade dos conselhos nos municípios pequenos. Esses dados são intrigantes, pois nos 
sugerem que a participação, na área da assistência social, impacta a gestão em maior grau em contextos nos quais sua qualidade é pior avaliada, ou seja, nos municípios de menor porte populacional. A expectativa era encontrar uma elevada correlação entre os índices nos municípios de maior porte populacional, porque esses concentram melhor desempenho nos indicadores de efetividade da participação e de gestão da política.

Ora, o que explicaria este achado controverso? Por que a efetividade das instituições participativas sobre a gestão da política importa sobretudo nos municípios de pequeno porte?

Assumimos, como hipótese, que a incidência maior do IEP sobre o IGM nos municípios de pequeno porte, comparativamente aos demais, seria explicado pela política de descentralização do SUAS, que implantou três níveis de gestão para o enquadramento dos municípios, de acordo com as capacidades estatais reunidas: gestão inicial, gestão básica e gestão plena. $\mathrm{O}$ enquadramento dos municípios em cada um desses níveis implica, para eles, mais ou menos incentivos e responsabilidades sobre a gestão da política de assistência social. Ou seja, os municípios enquadrados na gestão plena possuem mais autonomia para gerir a política, e também mais incentivos para exercer essa função (MDS 2005). Alguns estudos têm mostrado que os municípios maiores conseguem reunir as capacidades estatais necessárias ao enquadramento nos níveis mais avançados de gestão da política. Nessa direção, um estudo com os municípios do Paraná mostrou haver uma tendência de associação entre o porte do município e seu enquadramento nos níveis de gestão do SUAS: quanto maior o porte do município, maior sua participação relativa na gestão plena (Souza 2011). É plausível supor que encontremos essa mesma tendência para a realidade nacional.

Além disso, é preciso considerar que algumas exigências atribuídas aos municípios, como a quantidade de Centros de Referência de Assistência Social a ser mantida, varia dependendo do seu porte populacional (MDS 2005). Assim, constatamos que, de um lado, os municípios maiores tendem ao enquadramento em níveis de gestão elevada que implicam também maior responsabilidade sobre a política de assistência e, de outro, pesam sobre eles maiores exigências quanto ao oferecimento de alguns equipamentos e programas previstos no SUAS. A combinação desses dois fatores nos leva a constatar que a complexidade envolvida na organização e na gestão da política de assistência social varia conforme o porte. Assim, a complexidade da gestão da política é maior nas metrópoles e nos municípios de porte grande e médio, onde também encontramos maiores desigualdades sociais que exigem a articulação das políticas de assistência social com programas de outras áreas de políticas ${ }^{15}$. Nos municípios de pequeno porte, ao contrário, a complexidade da gestão dessa política é menor, o que parece permitir um efeito maior dos conselhos nos resultados da política municipal de assistência social.

Deste modo, sugerimos que o enquadramento da gestão da assistência social nos municípios menores contribui para explicar por que, nesses contextos, os conselhos obtêm desempenho melhor quanto aos efeitos sobre a gestão da política, embora, nesses casos, as IPs funcionem com menos qualidade (em termos de institucionalização, deliberação e representação) do que nos municípios grandes e nas metrópoles. Em outros termos, o nível de gestão da política na qual o município está enquadrado e as exigências que recaem sobre ele de acordo com seu porte, nas regras do SUAS, são elementos da política setorial que interferem na correlação entre o IEP e o IGM, e, portanto, também definidoras, nesse caso, das condições sob as quais os dois índices de relacionam. Assim, a forma como cada setor de política organiza a gestão interfere na intensidade do efeito da participação sobre a administração do setor. 
Cabe destacar, assim, que a responsabilidade pela qualidade da gestão da política (a despeito da qualidade da participação) estaria também associada às regras que configuram cada área de política pública, incluindo aí a maneira como está organizada a divisão de responsabilidades pelas diferentes esferas federativas na gestão e execução da política. Por outro lado, isso não quer dizer que o conselho com uma participação bem avaliada não melhore a política, mas, comparativamente aos conselhos de municípios menores, a sua incidência na gestão é menor.

Uma questão subsidiária é quanto aos efeitos do IEP desagregado no IGM, segmentado por porte de município. Geralmente, os estudos não abordam como as diferentes dimensões da qualidade da participação interagem na produção de efeitos na política pública. Neste aspecto, a pesquisa constata que os três subíndices do IEP produzem efeitos variados no IGM. Considerando separadamente a incidência dos níveis institucionalização, deliberação e representação sobre a gestão da política, por ordem de efeitos, temos: o nível 2 (deliberação) como o que mais impacta o IGM, seguido do nível 1 (institucionalização) e do nível 3 (representação).

Para esta análise, replicamos o modelo de regressão com o IEP desagregado e o IGM como critério, segmentando por porte dos municípios, obtendo-se um modelo para cada porte (Tabela 4). Constatamos diferentes resultados para cada porte, seja quanto ao poder explicativo de cada modelo (R quadrado ajustado), seja quanto ao coeficiente parcial (B), que quantifica o impacto que a variação de cada subíndice produz no IGM. De primeira mão, temos algo similar ao visto anteriormente: o conjunto dos subíndices do IEP explicam uma parcela maior da variação do IGM nos municípios pequenos I e II, seguidos pelos grandes e médios, nesta ordem $(21 \%, 14 \%, 12 \%$ e $9 \%)$. Desse modo, o efeito maior do IEP sobre o IGM nos municípios de pequeno porte é extensivo ao índice de efetividade da participação desagregado.

Tabela 4 - Regressão linear IEP - Desagregado x IGM, segundo o porte

\begin{tabular}{|c|c|c|c|c|c|}
\hline Porte & IEP. Desagregado & B & Beta & Sig. & Adjusted R Square \\
\hline \multirow[t]{4}{*}{ Pequeno I } & (Constant) & 0,232 & & 0,000 & $21 \%$ \\
\hline & N1 Institucionalização & 0,114 & 0,162 & 0,000 & \\
\hline & N2 Deliberação & 0,160 & 0,255 & 0,000 & \\
\hline & N3 Representação & 0,139 & 0,160 & 0,000 & \\
\hline \multirow[t]{4}{*}{ Pequeno II } & (Constant) & 0,344 & & 0,000 & $14 \%$ \\
\hline & N1 Institucionalização & 0,059 & 0,082 & 0,013 & \\
\hline & N2 Deliberação & 0,150 & 0,246 & 0,000 & \\
\hline & N3 Representação & 0,118 & 0,142 & 0,000 & \\
\hline \multirow[t]{4}{*}{ Médio } & (Constant) & 0,411 & & 0,000 & $9 \%$ \\
\hline & N1 Institucionalização & 0,114 & 0,163 & 0,007 & \\
\hline & N2 Deliberação & 0,122 & 0,206 & 0,002 & \\
\hline & N3 Representação & 0,005 & 0,007 & 0,912 & \\
\hline \multirow[t]{4}{*}{ Grande } & (Constant) & 0,383 & & 0,000 & $12 \%$ \\
\hline & N1 Institucionalização & 0,129 & 0,152 & 0,022 & \\
\hline & N2 Deliberação & 0,150 & 0,211 & 0,002 & \\
\hline & N3 Representação & 0,091 & 0,101 & 0,119 & \\
\hline
\end{tabular}

Fonte: Elaborado pelos autores, a partir do Censo SUAS (2012). 
Em relação ao Beta, em todos os portes, a deliberação (N2) apresentou-se como o subíndice mais importante, seguido da institucionalização, exceto para os municípios pequeno II. Por fim, temos o subíndice da representação, exceto nos municípios grandes e médios, onde ele não obteve significância. Quanto ao impacto que a variação de cada subíndice causa no IGM, temos a seguinte configuração: a institucionalização produz mais efeitos nos grandes municípios, seguido dos médios e pequenos I, empatados, e os pequenos II. Quanto à deliberação, ela produz mais efeitos que os demais níveis, mas é nos pequenos I que seu impacto é maior, seguido dos pequenos II e grandes, empatados, e dos médios. Em relação à representação, os efeitos maiores estão nos pequenos municípios, I e II. No restante, esse subíndice não obteve significância no modelo considerado.

Esses dados nos permitem concluir que os subíndices do IEP, tanto em escala nacional quanto por porte de município, caminham em uma mesma direção, produzindo efeitos na gestão da política. Porém, a despeito de não obtermos significância em alguns subíndices de municípios de determinados portes, observamos variações na relevância de cada um deles em termos do efeito produzido no IGM. Ou seja, as dimensões constitutivas da participação, concebidas separadamente, produzem impactos de magnitude distinta na gestão, apesar de seguirem no mesmo sentido. Nesse caso, um subíndice opera em detrimento do outro, pois, ao interagirem, a deliberação desponta como mais impactante em prejuízo da institucionalização e da representação. Essa ascensão é compreensível se considerarmos que é o subíndice que agrega precisamente as variáveis indicativas da incidência dos conselhos na gestão da política pública. A institucionalização, por mais importante que seja, ocupa um lugar secundário quando posta em interação com outras dimensões da participação. Os conselhos municipais da assistência social no país ultrapassaram a barreira dos primeiros oito anos de vida, conforme Gurza Lavalle, Voigt e Serafim (2016), legando essa dimensão a um papel secundário frente aos outros desafios, principalmente no âmbito da deliberação e da representação.

\section{Conclusões}

A agenda de estudos sobre a efetividade das Instituições Participativas está desafiada a inovar seus desenhos de pesquisa de modo a produzir diagnósticos mais precisos a respeito de seus efeitos nas políticas públicas. Em que pese as dificuldades metodológicas de aferir relações causais entre participação e resultados de políticas, este trabalho procurou oferecer uma contribuição por meio de análises estatísticas, tomando como base empírica os dados censitários do SUAS sobre o funcionamento dos conselhos municipais de assistência social e da gestão municipal nesse setor de política. A operacionalização empírica se deu a partir da construção de dois índices - o Índice de Efetividade da Participação (IEP) e o Índice de Gestão Municipal (IGM) - o que nos possibilitou responder as indagações acerca da existência de associações relativas entre ambos.

O Índice de Efetividade da Participação (IEP) mensurou a participação nos conselhos municipais de assistência social a partir de indicadores e variáveis selecionadas, validadas e compostas por três subíndices desagregáveis entre si: institucionalização, deliberação e representação. Esses subíndices atestam, respectivamente: (a) sua formalização, regras de funcionamento e enraizamento institucional; (b) seu grau de deliberação, tomada de decisões e conexões com o entorno; (c) seu grau de representatividade, divulgação das ações e ancoragem societária.

O Índice de Gestão Municipal (IGM) avaliou o desempenho da gestão da política setorial por meio de indicadores de "capacidades estatais" ou técnico- 
administrativas: estrutura institucional do setor, oferta de serviços e benefícios e estrutura de recursos humanos.

A caracterização geral do IEP e do IGM apontou que o desempenho de ambos os índices varia conforme o pertencimento regional e o porte populacional dos municípios brasileiros. Por um lado, as regiões Sul e Sudeste demonstraram os melhores resultados, comparativamente às regiões Norte e à média nacional. Por outro lado, a análise do comportamento dos índices denotou que os municípios de maior porte tendem a obter melhor desempenho. Ou seja, o alto desempenho dos índices se concentra nos municípios das regiões Sudeste e Sul, bem como de porte populacional grande e metropolitano, em detrimento das demais regiões e portes. Cabe mencionar que os índices não são internamente homogêneos e que heterogeneidades internas foram expostas, seja no recorte regional, seja no populacional. Contudo, a região e o porte populacional dos municípios se confirmam como condições que interferem na efetividade da participação na gestão municipal da política de assistência social. Também encontramos indícios que sugerem a importância da longevidade dos conselhos nessa configuração, principalmente quando focamos os municípios pequenos da região Norte. Além disso, por mais que, no modelo de regressão, a variável longevidade tenha apresentado efeitos reduzidos, ela se fez presente como um preditor do IGM.

Por seu turno, a análise da correlação entre os índices, por meio de testes estatísticos de regressão linear e agrupamentos de homogeneidade, aferiu a associação relativa entre IEP e IGM. Ora, a efetividade da participação nos conselhos afeta positivamente o desempenho da gestão da política, no nível municipal, convergindo com as expectativas teóricas e alguns estudos empíricos. Outrossim, este desfecho é corroborado na aplicação do IEP desagregado. Ponderando seus subíndices, o nível deliberação é o que produz mais efeitos no IGM, gerando resultados positivos na gestão da assistência social, seguido pelo nível institucionalização e, então, representação. A destacada performance da deliberação é compreensível se considerarmos que as variáveis que o compõem são aquelas associadas à gestão da política setorial.

Finalmente, na discussão sobre as condições sob as quais a participação importa para a gestão da política de assistência social, é notória a importância do porte populacional na relação entre os índices. Nosso principal achado é que o IEP explica uma parcela maior da variação do IGM nos municípios de menor porte, os quais, precisamente, obtém desempenho pior no IEP. Isso se dá porque processos participativos se correlacionam a maiores efeitos na gestão da política de assistência social nos contextos nos quais eles operam com menor qualidade. Para explicar esse achado, sugerimos observar as regras de enquadramento da gestão da política de assistência social, segundo as capacidades estatais dos municípios e das exigências que elas demandam de acordo com o porte populacional. Nos municípios de pequeno porte, a complexidade da gestão dessa política também é menor, o que parece permitir um efeito maior dos conselhos na maneira como se desenvolve a política de assistência social. Nesse aspecto, $o$ estudo demonstra que há condicionantes vinculados à forma como cada política pública está configurada institucionalmente, e que agem na relação entre participação e gestão.

IEuzeneia Carlos (euzeneiacarlos@gmail.com) é Doutora em Ciência Política pela USP, pesquisadora e professora do Programa de Pós-Graduação em Ciências Sociais da Universidade Federal do Espírito Santo (UFES). Vínculo institucional: Programa de Pós-Graduação em Ciências Sociais da Universidade Federal do Espírito Santo (UFES), Vitória, ES, Brasil.

IIRafael da Silva (eu_fael@yahoo.com.br) é Doutor em Sociologia Política pela UFSC, pesquisador e professor do Programa de Pós-Graduação em Ciências Sociais da Universidade Estadual de Maringá (UEM). Vínculo institucional: Programa de Pós-Graduação em Ciências Sociais da Universidade Estadual de Maringá (UEM), Maringá, PR, Brasil. 


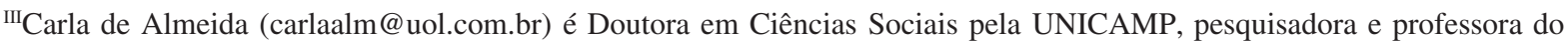
Programa de Pós-Graduação em Ciências Sociais da Universidade Estadual de Maringá (UEM). Vínculo institucional: Programa de Pós-Graduação em Ciências Sociais da Universidade Estadual de Maringá (UEM), Maringá, PR, Brasil.

\section{Referências}

Abelson, J. \& Gauvin, F., 2006. Assessing the Impacts of Public Participation: Concepts, Evidence and Policy Implications. Canadian Policy Research Networks Research Report, 6, pp.1-46.

Almeida, C., 2013. Saldos e limites dos estudos sobre representação política nas Inovações Institucionais brasileiras. In $37^{\circ}$ Encontro Anual da Anpocs. Águas de Lindóia.

Almeida, C. \& Tatagiba, L., 2012. Os conselhos gestores sob o crivo da política: balanços e perspectivas. Serviço Social \& Sociedade, 109, pp.68-92. DOI: 10.1590/s0101-66282012000100005

Almeida, C.; Carlos, E. \& Silva, R., 2015. A participação importa? Efeitos dos conselhos gestores nas administrações públicas municipais. In $39^{\circ}$ Encontro Anual da Anpocs. Caxambu.

Almeida, C.; Carlos, E. \& Silva, R., 2016a. Efetividade da participação nos conselhos municipais de assistência social do Brasil. Opinião Pública, 22(2), pp.250-285. DOI: 10.1590/1807-01912016222250

Almeida, C.; Carlos, E. \& Silva, R., 2016b. Efetividade do controle social na política de assistência social. Relatório de Pesquisa. Maringá: UEM.

Almeida, D.R., 2010. Representação política nos Conselhos de saúde do Brasil. In I Seminário Internacional e III Seminário Nacional Movimentos Sociais, Participação e Democracia. Florianópolis: UFSC.

Almeida, D.R. \& Cunha, E.S.M., 2011. A análise da deliberação democrática: princípios, conceitos e variáveis. In R.R.C. Pires, ed. Efetividade das instituições participativas no Brasil: estratégias de avaliação. Brasília: IPEA.

Ananias, P., 2009. Qualificação e Reflexão Crítica - Prefácio. In MDS. Ministério do Desenvolvimento Social e Combate à Fome. Concepção e gestão da proteção social não contributiva no Brasil. Brasília: MDS/UNESCO.

Avritzer, L., 2007. Sociedade civil, instituições participativas e representação: da autorização à legitimação da ação. Dados, 50(3), pp.443-464. DOI: 10.1590/s0011-52582007000300001

Avritzer, L., 2010. Introdução. In L. Avritzer, ed. A dinâmica da participação local no Brasil. São Paulo: Cortez.

Couto, B.R., 2009. O Sistema Único de Assistência Social: uma nova forma de gestão da assistência social. In MDS. Ministério do Desenvolvimento Social e Combate à Fome. Concepção e gestão da proteção social não contributiva no Brasil. Brasília: MDS/UNESCO.

Cunha, E.; Almeida, D.R.; Faria, C.F. \& Ribeiro, U.C., 2011. Uma estratégia multidimensional de avaliação dos conselhos de políticas: dinâmica deliberativa, desenho institucional e fatores endógenos. In R.R.C. Pires, ed. Efetividade das instituições participativas no Brasil: estratégias de avaliação. Brasília: IPEA.

Cunha, E., 2009. Efetividade deliberativa: estudo comparado de Conselhos Municipais de Assistência Social (1997/2006). Tese de Doutorado. Belo Horizonte: Universidade Federal de Minas Gerais.

Cunha, E., 2010. A deliberação nos conselhos municipais de assistência social. Relatório de Pesquisa. Belo Horizonte: UFMG.

Donaghy, M., 2013. Civil Society and Participatory Governance: Municipal Councils and Social Housing Programs in Brazil. New York: Routledge.

Faria, C.F. \& Ribeiro, U.C., 2011. Desenho institucional: variáveis relevantes e seus efeitos sobre o processo participativo. In R.R.C. Pires, ed. Efetividade das instituições participativas no Brasil: estratégias de avaliação. Brasília: IPEA.

Gurza Lavalle, A.; Voigt, J. \& Serafim, L., 2016. O que fazem os Conselhos e quando o fazem? Padrões decisórios e o debate dos efeitos das Instituições Participativas. Dados, 59(3), pp.609-650. DOI: 10.1590/00115258201687

Gurza Lavalle, A. \& Isunza Vera, E.A., 2011. Trama da crítica democrática: da participação à representação e à accountability. Lua Nova, 84), pp.95-139.

Gurza Lavalle, A.; Houtzager, P. \& Castelo, G., 2006. Democracia, pluralização da representação e sociedade civil. Lua Nova, 67, pp.49-103. DOI: 10.1590/s0102-64452006000200004

Gurza Lavalle, A., 2011. Participação: valor, utilidade, efeitos e causa. In PIRES, R. R. C., ed. Efetividade das instituições participativas no Brasil: estratégias de avaliação. Brasília: IPEA, pp.33-42.

Lima, P.F.; Alencar, J.; Ribeiro, U. \& Cruxên, I., 2014. Conselhos Nacionais: elementos constitutivos para sua institucionalização. Textos para a Discussão, 1951. IPEA.

Lüchmann, L.H.H., 2007. A representação no interior das experiências de participação. Lua Nova, 70, pp.139-170.

Lüchmann, L.H.H., 2011. Associações, participação e representação. Combinações e tensões. Lua Nova, São Paulo, 84, pp.141-174. DOI: 10.1590/s0102-64452011000300006

Maroco, J. \& Garcia-Marques, T., 2006. Qual a fiabilidade do Alpha de Cronbach? Questões antigas e soluções modernas? Laboratório de Psicologia, 4(1), pp.65-90. DOI: 10.14417/lp.763

Ministério do Desenvolvimento Social e Combate à Fome, Secretaria Nacional de Assistência Social, 2005. Norma Operacional Básica Nob/SUAS. Construindo as bases para a implantação do Sistema Único de Assistência Social, Brasília, julho.

O’Faircheallaigh, C., 2010. Public Participation and Environmental Impact Assessment: Purposes, implications, and lessons for public policy making. Environmental Impact Assessment Review, 30(1), pp.19-27. DOI: 10.1016/j.eiar.2009.05.001

Saward, M., 2000. Introduction. In , ed. Democratic Innovations. Routledge: London. 
Silva, A.L.N. \& Souza, D.E., 2015. Mensurando a democracia nos governos estaduais: uma proposta para construção do índice de capacidade institucional dos conselhos de políticas públicas. Revista Eletrônica de Ciência Política, 6(1), pp.231-249. DOI: $10.5380 /$ recp.v6i1.37486

Silva, R.; Carlos, E. \& Almeida, C., 2016. A efetividade das Instituições Participativas: um estudo sobre a política de Assistência Social. In $40^{\circ}$ Encontro Anual da Anpocs. Caxambu.

Smith, G., 2009. Democratic Innovations. Designing institutions for citizen participation. New York: Cambridge University Press.

Souza, L.P., 2011. Gestão do Sistema Único de Assistência Social (SUAS) no Paraná: Limites e Possibilidades. Cadernos IPARDES, 1(1), pp.66-81.

Sposati, A., 2009. Modelo brasileiro de proteção social não contributiva: concepções fundamentes. In MDS. Ministério do Desenvolvimento Social e Combate à Fome. Concepção e gestão da proteção social não contributiva no Brasil. Brasília: MDS/UNESCO.

Petinelli, V., 2013. Contexto político, natureza política, organização da sociedade civil e desenho institucional: alguns condicionantes da efetividade das conferências nacionais. In L. Avritzer \& C.H.S. Leite, eds. Conferências Nacionais: atores, dinâmicas participativas e efetividade. Brasília: IPEA.

Pires, R. \& Vaz, A., 2010. Participação faz diferença? Uma avaliação das características e efeitos da institucionalização da participação nos municípios brasileiros. In L. Avritzer, ed. A dinâmica da participação no Brasil. São Paulo: Editora Cortez.

Vaz, A.C.N., 2011. Participação política, efeitos e resultados em políticas públicas: notas crítico-analíticas. Opinião Pública, 17(1), pp.163-205. DOI: 10.1590/s0104-62762011000100006

Zorzal, G. \& Carlos, E., 2017. Audiências públicas do Legislativo Estadual: fatores endógenos e exógenos na análise da efetividade da participação. Revista de Sociologia e Política, 25(64), pp.23-46. DOI: 10.1590/1678-987317256402

\section{Outras fontes}

IBGE. Instituto Brasileiro de Geografia e Estatística, 2013. Perfil dos estados brasileiros. Disponível em: ftp://ftp.ibge.gov.br/Perfil_Estados/2013/estadic2013.pdf. Acesso em: 19 set. 2018.

MDS. Ministério do Desenvolvimento Social e Combate à Fome, 2005. Concepção e gestão da proteção social não contributiva no Brasil. Brasília: MDS/UNESCO.

MDS. Ministério do Desenvolvimento Social e Agrário, 2012. Portal Censo SUAS. Disponível em: https://aplicacoes.mds.gov.br/sagirmps/portal-censo/. Acesso em: 19 set. 2018.

PNUD, 2013. Atlas do Desenvolvimento Humano do Brasil. Disponível em: http://atlasbrasil.org.br/2013/. Acesso em: 17 set. 2018.

Participation and public policy: effectiveness of social assistance councils in the management of politics

ABSTRACT Introduction: This article intend to contribute to debate on the effectiveness of Participatory Institutions, analyzing the effects of social assistance councils on the management of sectoral policy in Brazilian municipalities. Methods: Methodologically, the analysis establishes a statistical correlation between the effectiveness of the participation and the performance of the policy management, based on the construction of two indexes, the Participation Effectiveness Index (IEP) and the Municipal Management Index (IGM), using data from Census SUAS 2012. The first index aggregates indicators of the quality of participation expressed in the degree of institutionalization, deliberation and representation. The second group includes management performance variables in sectoral policy, measured in technical and administrative capacities present in municipalities. Results: The contribution of the article is to assess the effects of social assistance councils on sector policy, as well as to discuss under what conditions participation matters in the municipalities. It highlights two of them, which constrains the results of participation in policy management: regional location and population size. Discussion: It argues that the effectiveness of the participation explains a greater part of the variation in the performance of the management in the municipalities of smaller population size, which sends to the configuration of the public policy.

KEYWORDS: participatory institutions; brazilian counties; management councils; public administration; social assistance.

This is an Open Access article distributed under the terms of the Creative Commons Attribution Non-Commercial License which permits unrestricted non-commercial use, distribution, and reproduction in any medium provided the original work is properly cited. 


\section{Apêndice}

Quadro 1 - Variáveis que compõem o Nível 1: Institucionalização

\begin{tabular}{ll}
\hline Variáveis & Peso \\
\hline Qual o instrumento legal que criou o conselho? & Baixo \\
Qual o ano de publicação do instrumento que criou o conselho? & Baixo \\
O conselho possui regimento interno? & Baixo \\
O regimento especifica e detalha quais conteúdos? & Baixo \\
O conselho faz uso dos 3\% do índice de gestão descentralizada para custear seu funcionamento? & Alto \\
O conselho possui sede específica? & Médio \\
Quais equipamentos e materiais estão disponíveis para o conselho? & Baixo \\
O conselho possui secretaria executiva? & Alto \\
Quantos funcionários estão lotados na secretaria executiva? & Baixo \\
A secretaria executiva trabalha exclusivamente no conselho? & Médio \\
\hline
\end{tabular}

Fonte: Elaborado pelos autores, a partir do Censo SUAS (2012).

Quadro 2 - Variáveis que compõem o Nível 2: Deliberação

\begin{tabular}{|c|c|}
\hline Variáveis & Peso \\
\hline Com que frequência o conselho realiza reuniões ordinárias? & Médio \\
\hline O conselho tem calendário anual de reuniões ordinárias estabelecido? & Baixo \\
\hline $\begin{array}{l}\text { O conselho tem planejamento anual das fiscalizações realizadas para os serviços, programas da rede } \\
\text { pública e privada? }\end{array}$ & Médio \\
\hline $\begin{array}{l}\text { O conselho já regulamentou por resolução própria a inscrição das entidades e organizações de } \\
\text { assistência social, bem como os serviços, programa e benefícios socioassistenciais? }\end{array}$ & Alto \\
\hline O conselho tem comissões permanentes? & Médio \\
\hline $\begin{array}{l}\text { O conselho estabeleceu por resolução o plano de acompanhamento e fiscalização das entidades, bem } \\
\text { como dos serviços, programas e benefícios? }\end{array}$ & Alto \\
\hline $\begin{array}{l}\text { O conselho já regulamentou por resolução própria os Benefícios Eventuais concedidos no âmbito do } \\
\text { SUAS? }\end{array}$ & Alto \\
\hline O conselho deliberou sobre proposta anual de orçamento do Executivo? & Baixo \\
\hline $\begin{array}{l}\text { O conselho fiscaliza os serviços, programas, projetos e benefícios do SUAS para a rede } \\
\text { pública, privada ou para ambas? }\end{array}$ & Baixo \\
\hline O conselho acompanha a execução dos Planos de Ação das entidades? & Alto \\
\hline O conselho delibera sobre os critérios de repasse de recursos para as entidades? & Alto \\
\hline Com que frequência o gestor apresenta ao conselho relatório de aplicação dos recursos do fundo? & Médio \\
\hline $\begin{array}{l}\text { O conselho aprecia e emite parecer sobre o demonstrativo sintético de execução físico-financeiro do } \\
\text { Executivo? }\end{array}$ & Baixo \\
\hline O conselho aprecia e emite parecer sobre a execução financeira dos recursos do fundo? & Baixo \\
\hline O conselho acompanha a pactuação da Comissão Intergestora Tripartite? & Alto \\
\hline O conselho conhece e acompanha o Plano Decenal da Assistência? & Alto \\
\hline O conselho acompanha o cumprimento das deliberações da conferência? & Alto \\
\hline
\end{tabular}

Fonte: Elaborado pelos autores, a partir do Censo SUAS (2012). 
Quadro 3 - Variáveis que compõe o Nível 3: Representação

\begin{tabular}{ll}
\hline Variáveis & Peso \\
\hline O presidente e vice-presidente são eleitos em reunião plenária do conselho? & Alto \\
Há alternância na presidência entre os representantes do governo e da sociedade civil? & Alto \\
Como são eleitos os representantes da sociedade civil? & Alto \\
No município existe algum Fórum de discussão do SUAS? & Alto \\
Com que frequência o conselho realiza reuniões ampliadas? & Alto \\
Com que frequência o conselho realiza reuniões descentralizadas? & Alto \\
Com que frequência o conselho realiza ações de mobilização social? & Alto \\
As atas do conselho são tornadas públicas para a sociedade e entidades? & Alto \\
As deliberações/resoluções do conselho são publicadas em Diário Oficial? & Baixo \\
O conselho tem canal de recebimento de denúncias? & Médio \\
\hline
\end{tabular}

Fonte: Elaborado pelos autores, a partir do Censo SUAS (2012).

Quadro 4 - Variáveis que compõem o IGM

\section{Variáveis}

De acordo com a estrutura administrativa do município, o órgão gestor da assistência social caracteriza-se como: (a) secretaria exclusiva; (b) conjunta; (c) Fundação Pública

A gestão do Cadastro Único para Programas Sociais do Governo Federal (CadÚnico), no município, é realizado pelo órgão gestor da Assistência Social?

Existe Lei Municipal de regulamentação do Sistema Único da Assistência Social (SUAS)?

Existe algum tipo de parceria entre a Secretaria de Assistência Social e o Ministério Público ou Poder Judiciário ou a Defensoria Pública?

O município possui Plano Municipal de Assistência Social (PMAS) aprovado pelo Conselho Municipal de Assistência Social?

O FMAS é uma unidade orçamentária?

O órgão gestor municipal faz transferência de recursos por convênio para ONGs ou Entidades de Assistência Social no município?

O órgão gestor municipal da assistência social tem Plano de Cargos, Carreiras e Salários (PCCS) implantado?

Considerando apenas os trabalhadores lotados na sede do Órgão Gestor Municipal da Assistência Social (e nas administrações regionais, caso existam), indique o quantitativo de acordo com o vínculo e escolaridade (NÃO considerar os trabalhadores que estão lotados nas unidades públicas que ofertam serviços socioassistenciais):

No ano de 2011 os trabalhadores da Assistência Social do município tiveram acesso a cursos presenciais de capacitação?

No ano de 2011 os trabalhadores da Assistência Social do município tiveram acesso a cursos à distância (EAD) de capacitação?

O Órgão Gestor da Assistência Social instituiu Central de Vagas para o Acolhimento Institucional de Crianças e Adolescentes, destinada a monitorar as vagas de acolhimento, indicando o serviço que melhor atenda às necessidades específicas de cada caso encaminhado?

A Assistência Social do município tem programa/serviço de apoio e proteção a pessoas e famílias afetadas por situação de emergência ou de calamidade pública?

O órgão gestor municipal da Assistência Social concede benefícios eventuais?

O município possui programa PRÓPRIO de transferência de renda (transferência de recursos municipais de forma constante a um público específico)?

A organização da oferta de serviços socioassistenciais é planejada com base em diagnóstico territorial das necessidades e demandas da população?

O órgão gestor utiliza sistema de informação próprio para gerenciar a política de Assistência Social?

Existe algum tipo de estudo setorial e/ou diagnóstico socioeconômico do município (vocação, potencialidade, matéria prima, mercado e iniciativas existentes) que tenha sido realizado nos últimos 5 anos? 
O governo municipal desenvolve ações, programas ou projetos de inclusão produtiva para geração de trabalho e renda? O governo municipal desenvolve ações, programas ou projetos de formação, qualificação ou capacitação profissional?

O governo municipal tem algum programa/projeto específico para inclusão social das pessoas com deficiência nas escolas de ensino regular?

O governo municipal tem algum programa/projeto específico para inclusão social de pessoas com deficiência no mercado de trabalho?

Quais serviços de proteção social básica são ofertados pelo município?

Quais serviços de proteção social especial de média complexidade são ofertados pelo município?

Que serviços de proteção social especial de alta complexidade são ofertados pelo município?

Especifique quais as ações relativas ao Benefício de Prestação Continuada (BPC) são desenvolvidas pela Assistência Social no município:

Indique quais atividades relacionadas à Vigilância Socioassistencial são realizadas pelo Órgão Gestor

Indique se as áreas abaixo estão constituídas como subdivisões administrativas (departamentos, coordenações) na estrutura do órgão gestor

Fonte: Elaborado pelos autores, a partir do Censo SUAS (2012). 